\title{
Feasibility of Dual-Task Gait Training for Community-Dwelling Adults after Stroke: A Case Series
}

\author{
Prudence Plummer, ${ }^{1}$ Raymond M. Villalobos, ${ }^{2}$ \\ Moira S. Vayda, ${ }^{2}$ Myriam Moser, ${ }^{2}$ and Erin Johnson ${ }^{2}$ \\ ${ }^{1}$ Division of Physical Therapy, Department of Allied Health Sciences, The University of North Carolina at Chapel Hill, \\ 3020 Bondurant Hall, Campus Box No. 7135, Chapel Hill, NC 27599, USA \\ ${ }^{2}$ New England Rehabilitation Hospital, Woburn, MA 01801, USA \\ Correspondence should be addressed to Prudence Plummer; pplummer@med.unc.edu
}

Received 26 August 2013; Revised 14 February 2014; Accepted 3 March 2014; Published 9 April 2014

Academic Editor: Valery Feigin

Copyright (C) 2014 Prudence Plummer et al. This is an open access article distributed under the Creative Commons Attribution License, which permits unrestricted use, distribution, and reproduction in any medium, provided the original work is properly cited.

This case series explored the feasibility and efficacy of cognitive-motor dual-task gait training in community-dwelling adults within 12 months of stroke. A secondary aim was to assess transfer of training to different dual-task combinations. Seven male participants within 12 months of stroke participated in 12 sessions of dual-task gait training. We examined single and dual-task performance in four different dual-task combinations at baseline, after 6 and 12 sessions, and if possible, at 1-month followup. Feasibility was assessed by asking participants to rate mental and physical fatigue, perceived difficulty, anxiety, and fear of falling at the end of each session. Five of the seven participants demonstrated reduced dual-task cost in gait speed in at least one of the dual-task combinations after the intervention. Analysis of the patterns of interference in the gait and cognitive tasks suggested that the way in which the participants allocated their attention between the simultaneous tasks differed across tasks and, in many participants, changed over time. Dual-task gait training is safe and feasible within the first 12 months after stroke, and may improve dual-task walking speed. Individuals with a combination of physical and cognitive impairments may not be appropriate for dual-task gait training.

\section{Introduction}

Cognitive-motor dual-task interference, defined as the decrement in performance that occurs when cognitive and motor tasks are performed simultaneously, has been well established in people after stroke [1-9]. This growing body of research has demonstrated significant dual-task decrements in gait speed $[1,5,8]$, stride length $[5,8]$, cadence $[6,8]$, stride duration $[2$, $4,8]$, and double limb support duration $[1,7]$. In other words, compared to single-task walking, when individuals with stroke perform a cognitive task while walking they are less stable and take shorter, slower steps, resulting in a dramatic cost on gait speed. Gait-related dual-task deficits persist in community-dwelling stroke survivors many months after discharge from rehabilitation $[3,5,8]$. Since walking in the community is often performed concurrently with cognitive tasks, such as remembering directions or engaging in social interactions, a reduced capacity for dual-task walking may restrict the degree to which a person is able to physically function and participate in their life roles.

Conventional rehabilitation does not appear to adequately address gait-related dual-task interference. For example, in a longitudinal study of cognitive-motor interference, Cockburn and colleagues [2] found that 7 out of 10 patients showed a reduction in gait decrement associated with dualtask walking after usual rehabilitation; however, most patients continued to exhibit considerable dual-task interference during walking at discharge. Thus, even though single-task gait speed may recover to normal values after rehabilitation for stroke, dual-task capacity can remain considerably impaired.

There is promising evidence for dual-task training in older adults $[10,11]$ and individuals with Parkinson's disease $[12,13]$. A recent study examined the effects of a cognitivemotor dual-task gait training intervention in people with neurological disorders [14], but only 2 of the 10 participants in the experimental group had experienced a stroke. 
TABLE 1: Overview of gait activities for dual-task gait training.

\begin{tabular}{lll}
\hline \multicolumn{1}{c}{ Predictable } & Unpredictable \\
\hline \multirow{5}{*}{ Stationary } & $\begin{array}{l}\text { Closed tasks } \\
\text { (i) Walking in flat, wide space } \\
\text { (ii) Walking over/around obstacles, all of the same height and equally } \\
\text { spaced } \\
\text { (iii) Walking with narrow BOS }\end{array}$ & $\begin{array}{l}\text { Variable motionless tasks } \\
\text { (i) Walking around obstacles with variable spacing } \\
\text { (ii) Walking over obstacles of variable height } \\
\text { (iii) Walking over changing floor surfaces }\end{array}$ \\
\hline \multirow{2}{*}{ Moving } & $\begin{array}{l}\text { Consistent motion tasks } \\
\text { (i) Walk toward/beside/behind a person moving at a consistent speed } \\
\text { and direction } \\
\text { (ii) Walk under different lighting conditions }\end{array}$ & $\begin{array}{l}\text { Open tasks } \\
\text { (i) Walking in a crowded corridor } \\
\text { (ii) Walking outdoors in the car park } \\
\text { (iii) Walking and negotiating a moving obstacle }\end{array}$ \\
\hline
\end{tabular}

To date, the only published dual-task training study in stroke is a dual-task exercise program involving patients with chronic stroke who walked while manipulating either one or two balls of various sizes (i.e., a motor-motor dualtask) [15]. Training was provided for 30 minutes, 3 times per week for 4 weeks. Compared to 12 patients who did not receive any intervention, the 13 patients who received dual-task training significantly improved their gait speed, cadence, stride duration, and stride length in single and dualtask (tray carrying) walking. Because this study focused on the coordination of simultaneous motor tasks and did not include any follow up, it is not known whether improvements transferred to other types of dual-tasks, such as cognitivemotor dual-tasks, or whether the improvements were maintained.

It is now well recognized that dual-task interference is influenced by the nature and difficulty of the cognitive tasks [9]. In a classic example, Maylor and Wing [16] found that age-related differences in postural stability were increased by cognitive tasks involving visuospatial cognition but not by counting tasks. Similar findings have been reported in gait-related dual-task interference in people with stroke [8]. Although these findings could be due to differences in task complexity, it is possible that the distinct cognitive processing demands of the tasks interfere differentially with postural control or gait, especially since gait is multifaceted with regard to its underlying cortical control mechanisms [17]. For this reason, it could be hypothesized that dual-task training in one type of task (e.g., executive function task) would not transfer to another type of cognitive task (e.g., visuospatial cognition task). Knowing whether the effects of dual-task training transfer to untrained dual-task combinations is essential for designing and planning rehabilitation interventions.

The purposes of this case series were to explore the feasibility and efficacy of a cognitive-motor dual-task training paradigm in community-dwelling adults within 12 months of stroke and to explore transfer of training to different dual-task combinations. To gain insight into whether dualtask gait training transfers across dual-task combinations, we examined the effects of the intervention on three different cognitive-motor dual-tasks and, where feasible, one motormotor dual-task.

\section{Case Descriptions}

The case series included participants within 12 months of stroke who had completed conventional rehabilitation and were living in the community. Participants had to be able to walk at least 10 meters without the assistance of another person, follow a three-step command, and communicate verbally in English. Individuals were not eligible to participate if they had any pre-existing neurological disorders other than stroke, a previous stroke with residual deficits, uncorrected hearing impairment, severe visual impairment, severe dysarthria or aphasia, lower extremity amputation, any orthopedic problem affecting gait, concurrent participation in a trial of locomotor, or cognitive rehabilitation or were not living in the community prior to their stroke. Participants were screened for eligibility and approved for participation by a physician. Seven participants were recruited and provided written informed consent to participate.

\section{Procedures}

Study procedures were approved by the Institutional Review Board at Northeastern University (Boston, MA). Following baseline testing, participants completed 12 sessions of dualtask gait training (DTGT), 30 minutes each session, 3 times per week for 4 weeks. Maximum time to complete all sessions was 6 weeks. A midpoint assessment was conducted after 6 sessions. Posttraining assessments were completed within one week following the last session. If possible, a follow-up assessment 1 month later was also conducted. All training sessions and assessments took place in the outpatient therapy department at New England Rehabilitation Hospital (Woburn, MA). Licensed physical therapists were trained to provide the study intervention, and a trained research assistant conducted all of the outcome assessments.

\section{Intervention}

DTGT consisted of gait activities performed simultaneously with cognitive tasks. Gait training activities were based on Gentile's taxonomy of tasks [18]; the progressive sequence of gait training activities is presented in Table 1. Five categories of cognitive tasks with different levels of difficulty were used 
TABLE 2: Summary of cognitive tasks for dual-task gait training.

\begin{tabular}{|c|c|}
\hline Task & Description \\
\hline $\begin{array}{l}\text { Random number/letter } \\
\text { generation }\end{array}$ & $\begin{array}{l}\text { (i) Randomly naming numbers between } 100 \text { and } 500 \text { (without repetition or consecutively) } \\
\text { (ii) Randomly naming odd (or even) numbers between } 1 \text { and } 100 \text { (without repetition or consecutively) } \\
\text { (iii) Randomly naming consonants of the alphabet (without repetition or consecutively) }\end{array}$ \\
\hline Word association & $\begin{array}{l}\text { Easy: } \\
\text { (i) naming as many words as possible in a category (e.g., animals, fruits) } \\
\text { (ii) naming opposites of words } \\
\text { Hard: } \\
\text { (i) naming as many words as possible beginning with a particular letter } \\
\text { (ii) naming as many words as possible in a category (e.g., European cities) }\end{array}$ \\
\hline Working memory & $\begin{array}{l}\text { Easy: } \\
\text { (i) reciting a sequence of numbers ( } 3 \text { or } 4 \text { number sequences) } \\
\text { (ii) reciting grocery list (3-4 items) } \\
\text { Hard: } \\
\text { (i) reciting a sequence of numbers ( } 5 \text { numbers per sequence) } \\
\text { (ii) reciting grocery items ( } 5 \text { items) }\end{array}$ \\
\hline Calculating a time & $\begin{array}{l}\text { Easy: } \\
\text { adding or subtracting minutes to a given time within the hour } \\
\text { (e.g., } 3: 15+5 \text { minutes; } 1: 30-15 \text { minutes) } \\
\text { Hard: } \\
\text { adding or subtracting minutes to a given time into the next hour } \\
\text { (e.g., 4:40 }+25 \text { minutes; } 1: 15-30 \text { minutes) }\end{array}$ \\
\hline Backward recitation & $\begin{array}{l}\text { (i) Reciting number sequences backward } \\
\text { (ii) Months of the year } \\
\text { (iii) Days of the week } \\
\text { (iv) Backward spelling ( } 4-5 \text { letter words) } \\
\text { (v) Counting backward (by 2,3,6, 7, and 8; starting between } 75 \text { and 100) }\end{array}$ \\
\hline
\end{tabular}

for the dual-task training (Table 2). The cognitive tasks used for DTGT were adapted from tasks used in previous dualtask training studies [10-12] and were selected to represent a range in level of difficulty. Tasks involving generation of spontaneous speech (e.g., telling a story) and visuospatial cognition (e.g., visualizing and reciting directions) were purposely excluded from the intervention regimen so that transfer of training to untrained tasks, such as these, could be assessed. The participants performed at least two different cognitive tasks in each training session.

Cognitive tasks were progressed according to individual abilities and progression occurred in concert with the progression of gait activities. The cognitive aspect of DTGT could be progressed in two ways: level of difficulty within the task (e.g., reciting a longer list of items from memory) or the category of task, recognizing that perceived task difficulty may vary between participants. For example, someone who is "good with numbers" might find the arithmetic-based tasks less difficult than someone who is not strong in arithmetic. Gait activities could be progressed by increasing speed, increasing the duration of continuous walking bouts, and changing the category/nature of the task (i.e., closed task versus open task). Therapists were instructed to ensure training activities were challenging, but not impossible, and were encouraged to try to progress training in both cognitive and gait domains within each session. However, several factors concerning the interaction between gait and cognitive tasks needed to be considered when progressing intervention activities. For example, walking speed may need to be decreased initially when a cognitive task is made more difficult; or an obstacle course activity may need to be made easier (e.g., closed task activity instead of variable activity) when a more difficult cognitive task is first attempted.

Therapists were provided with a comprehensive Manual of Procedures for the intervention and attended two 3-hour training sessions. The manual described each cognitive task and the progressive gait activities, as well as guidelines for progression of training. Therapists documented the duration, intensity, and type of treatment activities for each session on a standardized form. The importance of adhering strictly to the study protocol for the duration of the study was emphasized. The goal for all participants was to improve their ability to walk (increase speed, stride length, symmetry) while concurrently performing the cognitive tasks.

\section{Outcome Measures}

Gait and cognitive performances were assessed under singletask conditions and three different cognitive-motor dual-task conditions. Where feasible, we also assessed performance in a motor-motor dual-task. The three cognitive tasks were auditory Stroop, clock task, and spontaneous speech; the secondary motor task was a coin transfer task. The cognitive tasks were selected to represent different cognitive domains, one of which more closely resembled the cognitive activities used in training, while the others were considered "untrained" dual-task combinations (Table 3 ). 
TABLE 3: Dual-task assessments.

\begin{tabular}{ll}
\hline Task & Description \\
\hline Stroop task & $\begin{array}{l}\text { An executive function task representing the type of tasks trained during practice. } \\
\text { Participants hear the words "high" and "low," spoken in either a high pitch or a low } \\
\text { pitch; participants are instructed to report the pitch of the word (high/low), } \\
\text { ignoring the actual word }\end{array}$ \\
\hline Clock task & $\begin{array}{l}\text { A visuospatial cognition task. Participants are instructed to generate a mental } \\
\text { representation of a clock face and respond verbally (yes/no) based on where the } \\
\text { hands of the clock would be for the given times }\end{array}$ \\
\hline Spontaneous speech & $\begin{array}{l}\text { Spontaneous narrative in response to a stimulus question; highly relevant to } \\
\text { everyday dual tasking }\end{array}$ \\
\hline Coin-transfer task & Participants wear a belt with pockets and transfer coins from one pocket to another \\
\hline
\end{tabular}

In the auditory Stroop task [19] participants heard the words "high" and "low" spoken in either a high pitch $(360 \mathrm{~Hz})$ or a low pitch $(180 \mathrm{~Hz})$. The participants were instructed to indicate the pitch of the word they heard (ignoring the actual word presented) by responding "high" or "low" as quickly and as accurately as possible. In the clock task, the participants heard a time (e.g., ten-twenty-six) and were required to respond "yes" if the hands were in same half (left/right) and "no" if they were not. For the spontaneous speech task, speech samples were elicited using a set of questions designed to stimulate a verbal response lasting at least 30 seconds (e.g., tell me what you did on the weekend).

The coin transfer task, adapted from previous research $[20,21]$, involved participants transferring US 25-cent coins, one at a time using the dominant hand, from the dominantside "pocket" to the nondominant side as quickly as possible. The pockets $(16.5 \times 14.5 \mathrm{~cm})$ were attached to a belt worn around the participant's waist. In all dual-task conditions, the participants were not specifically instructed to prioritize either task because we were primarily interested in observing the spontaneous dual-task effects. Performance in both gait and nongait tasks was assessed in order to make inferences about attention prioritization and patterns of cognitivemotor interference during dual-task conditions [9].

Spatiotemporal metrics of gait were assessed using a 6meter GAITRite walkway, with a 2-meter runoff at each end to allow deceleration and turning. Participants completed 46 continuous passes for each task. The average of all GAITRite passes for each condition was used for analysis. Order of the dual-tasks (Stroop, clock, speech, and coin transfer) was randomized for each participant, but each person completed the tasks in the same order on each testing occasion. In this report, we focus on gait speed as the primary measure of gait performance due to its functional importance [22] and to enable comparison of findings to previous dual-task studies.

Single-task performance on the Stroop, clock, speech, and coin transfer tasks was performed immediately prior to the respective dual-task condition. Single-task performance for the coin transfer task was assessed whilst standing; for the cognitive tasks, single-task performance was assessed while sitting. Average reaction times (in milliseconds) and overall accuracy (percent correct) on the auditory Stroop and clock tasks were measured using DirectRT software (Empirisoft, New York, NY). Discourse analysis of the speech transcripts was performed to evaluate dual-task effects on speech. We focused on two measures of speech discourse: clauses per utterance, a measure of sentence complexity, and pauses per utterance. This decision was based on our previous research, which demonstrated that individuals with stroke experienced a significant dual-task effect on pauses per utterance but not on clauses per utterance [8]. In the coin transfer task, the number of coins transferred (max. 12) was recorded, and the coin transfer rate (coins/min) was calculated. In the singletask condition of the coin-transfer task, the participants transferred as many coins as possible in 30 seconds.

To examine the effects of the intervention on the amount of dual-task interference, we calculated dual-task effects (DTE) on gait speed and each secondary-task measure (i.e., reaction time, accuracy, speech variables, and coin transfer rate). The DTE represents the relative change in performance in the dual-task condition compared to single-task performance and is calculated by dividing the difference in value (e.g., gait speed) between single and dual-task performance by the value of the single-task performance, expressed as percentage [23]. Negative DTE indicates that performance deteriorated in the dual-task condition relative to single-task performance (dual-task cost), while positive DTE represents improvement in performance (dual-task benefit). For the Stroop and clock tasks, we calculated a composite DTE for cognitive-task performance by summing the DTE for reaction time and accuracy, which accounts for speed-accuracy tradeoffs in the overall DTE [23]. We computed a composite DTE for the speech variables (clauses per utterance, pauses per utterance) in the same way.

Secondary outcome measures were the Timed Up and Go (TUG) test [24], the Activities-specific Balance Confidence (ABC) scale [25], and the Subjective Index of Physical and Social Outcome (SIPSO) [26]. The secondary outcome measures were assessed before and after intervention and at the one-month follow up assessment. These measures were collected immediately after the assessment of dualtask interference described above. The order of secondary outcome assessments was consistent across participants and timepoints (pre, post, follow-up). Additionally, at baseline, the participants were assessed on a range of measures to characterize severity of impairment in cognition (Montreal Cognitive Assessment [27]), executive function (Stroop color-word interference test [28]), language ability (Shipley 
Vocabulary Test [29]), lower extremity motor function (Fugl Meyer et al. [30]), and depression (short form of the Geriatric Depression Scale [31]). The 6-minute walk test was conducted to provide a measure of walking endurance.

Feasibility of DTGT was assessed by measuring participants' perceptions of physical and mental fatigue as well as their perceptions of task difficulty, anxiety, and fear of falling on a $100-\mathrm{mm}$ visual analogue scale [12], where 0 represented no fatigue/anxiety/difficulty/fear, and 100 represented maximum levels of the construct. Adherence to the 12session training program was a further measure of feasibility. Safety of the intervention was assessed via monitoring of adverse events and falls. Overall patient acceptance of DTGT was measured using a feedback questionnaire regarding the participants' satisfaction with the intervention.

\section{Outcomes}

All seven participants completed 12 sessions of DTGT within 6 weeks (range: 3.7-5.4 weeks, mean: 4.3). One patient missed the midpoint assessment due to scheduling difficulties, and two participants were not available for the follow-up assessment. Only two participants were assessed on the motormotor dual-task combination. The reasons for not assessing other participants on the coin transfer task included inability to perform the task due to upper extremity hemiparesis or use of assistive device in the unaffected hand and insufficient time/minimizing testing fatigue. The baseline characteristics and demographics of the participants are presented in Table 4.

6.1. Gait Speed. Table 5 presents single and dual-task gait speeds for each participant at each assessment. Dual-task changes are shown in both absolute (gait speed, $\mathrm{m} / \mathrm{s}$ ) and relative (dual-task effects, \%) measures. Baseline singletask gait speeds ranged from $0.58 \mathrm{~m} / \mathrm{s}$ to $1.07 \mathrm{~m} / \mathrm{s}$ (mean: $0.84 \mathrm{~m} / \mathrm{s}$ ). After intervention, single-task gait speed was generally maintained in all participants (mean: $0.87 \mathrm{~m} / \mathrm{s}$, range: $0.66-1.10$ ). Of the five participants with follow-up data, three had further improvements in single-task gait speed at 1-month follow up. As illustrated in Table 5, all participants had dual-task declines in gait speed in all of the dualtask combinations at baseline, except for Participant 2 who essentially maintained single-task walking speed during the speech dual-task $(+0.01 \mathrm{~m} / \mathrm{s})$. After intervention, five of the seven participants demonstrated a reduced dual-task cost in gait speed in at least one of the dual-task combinations. Participant 3, who demonstrated an increase in single-task gait speed post intervention, only improved his dual-task walking speed in the speech dual-task. Participant 6 walked faster in all conditions after intervention, but continued to experience dual-task costs on gait speed in all three cognitivemotor dual-tasks.

The effects of the intervention on absolute and relative dual-task costs on gait speed appeared to be different across dual-task combinations (Table 5). The most consistent improvements were observed for the Stroop task. At baseline, absolute dual-task declines in gait speed for the
Stroop task ranged from 0.03 to $0.38 \mathrm{~m} / \mathrm{s}$ (mean: $0.13 \mathrm{~m} / \mathrm{s}$ ). After intervention, four participants (P1, P2, P4,and P5) had noticeably smaller dual-task declines in gait speed (range for all participants: $-0.01-0.17 \mathrm{~m} / \mathrm{s}$, mean: $0.06 \mathrm{~m} / \mathrm{s}$ ). The improvements in gait-related dual-task performance were less consistent and, on average, of smaller magnitude for the clock and speech tasks. Baseline dual-task declines in gait speed during the clock task ranged from 0.05 to $0.22 \mathrm{~m} / \mathrm{s}$ (mean: $0.11 \mathrm{~m} / \mathrm{s}$ ); after intervention the dual-task declines were $0.00-0.16 \mathrm{~m} / \mathrm{s}$ (mean: $0.09 \mathrm{~m} / \mathrm{s}$ ). For the speech task, baseline dual-task declines in gait speed ranged from -0.01 to $0.23 \mathrm{~m} / \mathrm{s}$ (mean: $0.11 \mathrm{~m} / \mathrm{s}$ ); after intervention the dual-task declines were $0.02-0.31 \mathrm{~m} / \mathrm{s}$ (mean: $0.14 \mathrm{~m} / \mathrm{s}$ ). The two participants who performed the coin transfer task slowed their gait speed at baseline by $0.20 \mathrm{~m} / \mathrm{s}$ (Participant 1 ) and $0.12 \mathrm{~m} / \mathrm{s}$ (Participant 4); after intervention the dual-task declines were $0.19 \mathrm{~m} / \mathrm{s}$ (Participant 1) and $0.00 \mathrm{~m} / \mathrm{s}$ (Participant 4).

The magnitude of the absolute dual-task decline in gait speed at baseline meant that three of the four participants with usual gait speed $\geq 0.80 \mathrm{~m} / \mathrm{s}(\mathrm{P} 4, \mathrm{P} 5, \mathrm{P} 7)$ walked $<0.80 \mathrm{~m} / \mathrm{s}$ in at least one of the dual-task conditions. This is important, since $0.8 \mathrm{~m} / \mathrm{s}$ is the widely considered threshold for functional community ambulation $[22,32]$. Thus, the dual-task decline in these participants is clinically significant; they were unable to maintain gait speed needed for functional community ambulation when walking while performing a cognitive task. After intervention, all three of these participants had dualtask gait speeds $>0.80 \mathrm{~m} / \mathrm{s}$ for the Stroop and clock tasks, and two (P5 and P6) also walked $>0.80 \mathrm{~m} / \mathrm{s}$ during the speech task. These represent clinically meaningful improvements, since dual-task walking speeds have crossed into the range needed for full community ambulation $[22,32]$. Of the three participants with single-task gait speed $<0.80 \mathrm{~m} / \mathrm{s}$ at baseline (i.e., functionally limited community ambulators during single-task walking), two (P1 and P2) had improved dualtask gait speeds in all dual-task conditions at the 1-month follow up, but remained $<0.70 \mathrm{~m} / \mathrm{s}$. Participant 3 was the only participant to walk slower than $0.60 \mathrm{~m} / \mathrm{s}$ at baseline. Although his gait speed increased to $0.66 \mathrm{~m} / \mathrm{s}$ after intervention, this was not retained at follow up. Despite improved dual-task walking speed in the speech dual-task after intervention, his relative dual-task costs after intervention were worse than at baseline (Table 5).

6.2. Pattern of Cognitive-Motor Interference. To examine changes in the pattern of cognitive-motor interference, we plotted the DTE on gait speed (DTEg) against the DTE on cognitive-task performance (DTEc) for each subject for the three cognitive-motor dual-task combinations before and after the intervention. Figure 1 explains the patterns of cognitive-motor interference, and Figure 2 presents the individual cognitive-motor interference patterns at baseline and postintervention assessments.

The data in Figure 2 indicate clearly the consistent negative DTE on gait speed (i.e., DTEg values consistently below the horizontal dotted line) and a range of positive and negative DTE in the cognitive task (i.e., DTEc values left 
TABLE 4: Demographic and baseline characteristics of participants.

\begin{tabular}{|c|c|c|c|c|c|c|c|c|c|c|c|c|}
\hline Participant & $\begin{array}{c}\text { Age } \\
\text { (years) }\end{array}$ & Gender & $\begin{array}{c}\text { Time since } \\
\text { stroke } \\
\text { (months) }\end{array}$ & $\begin{array}{c}\text { Side of } \\
\text { hemiplegia }\end{array}$ & Fugl-Meyer & $\mathrm{MoCA}$ & Stroop test & Shipley & GDS & $\begin{array}{l}\text { Education } \\
\text { (years) }\end{array}$ & $6 \underset{(\mathrm{m})}{6 \text { min walk }}$ & $\begin{array}{c}\text { Assistive } \\
\text { device }\end{array}$ \\
\hline 1 & 72 & M & 12 & $\mathrm{~L}$ & 24 & 27 & 39 & 32 & 3 & 16 & 243.2 & None \\
\hline 2 & 74 & M & 11 & $\mathrm{R}$ & 25 & 25 & 49 & 31 & 3 & 16 & 230.9 & Cane \\
\hline 3 & 86 & M & 4.5 & $\mathrm{~L}$ & 26 & 23 & NT & 33 & 3 & 16 & 198.7 & Cane \\
\hline 4 & 42 & M & 11 & $\mathrm{~L}$ & 25 & 26 & 26 & 27 & 8 & 12 & 318.9 & None \\
\hline 5 & 76 & M & 8.5 & $\mathrm{~L}$ & 29 & 28 & 30 & 37 & 0 & 22 & 373.8 & None \\
\hline 6 & 60 & M & 9.3 & $\mathrm{~L}$ & 27 & 28 & 22 & 33 & 3 & 18 & 358.8 & Cane \\
\hline 7 & 86 & $\mathrm{M}$ & 3 & $\mathrm{R}$ & 26 & 27 & 45 & 37 & 2 & 22 & 324.5 & None \\
\hline Mean & 70.9 & & 8.5 & & 26.0 & 26.3 & 35.2 & 32.9 & 3.1 & 17.4 & 292.7 & \\
\hline SD & 15.5 & & 3.5 & & 1.6 & 1.8 & 10.8 & 3.5 & 2.4 & 3.6 & 68.0 & \\
\hline
\end{tabular}

Fugl-Meyer: Fugl-Meyer motor assessment for lower extremity (max. 34); MoCA: montreal cognitive assessment (maximum score 30); Stroop test: Stroop color-word interference score (color-word score minus color score); Shipley: Shipley vocabulary test (max. 40); GDS: geriatric depression scale (score > 5 indicates depression); NT: not tested.

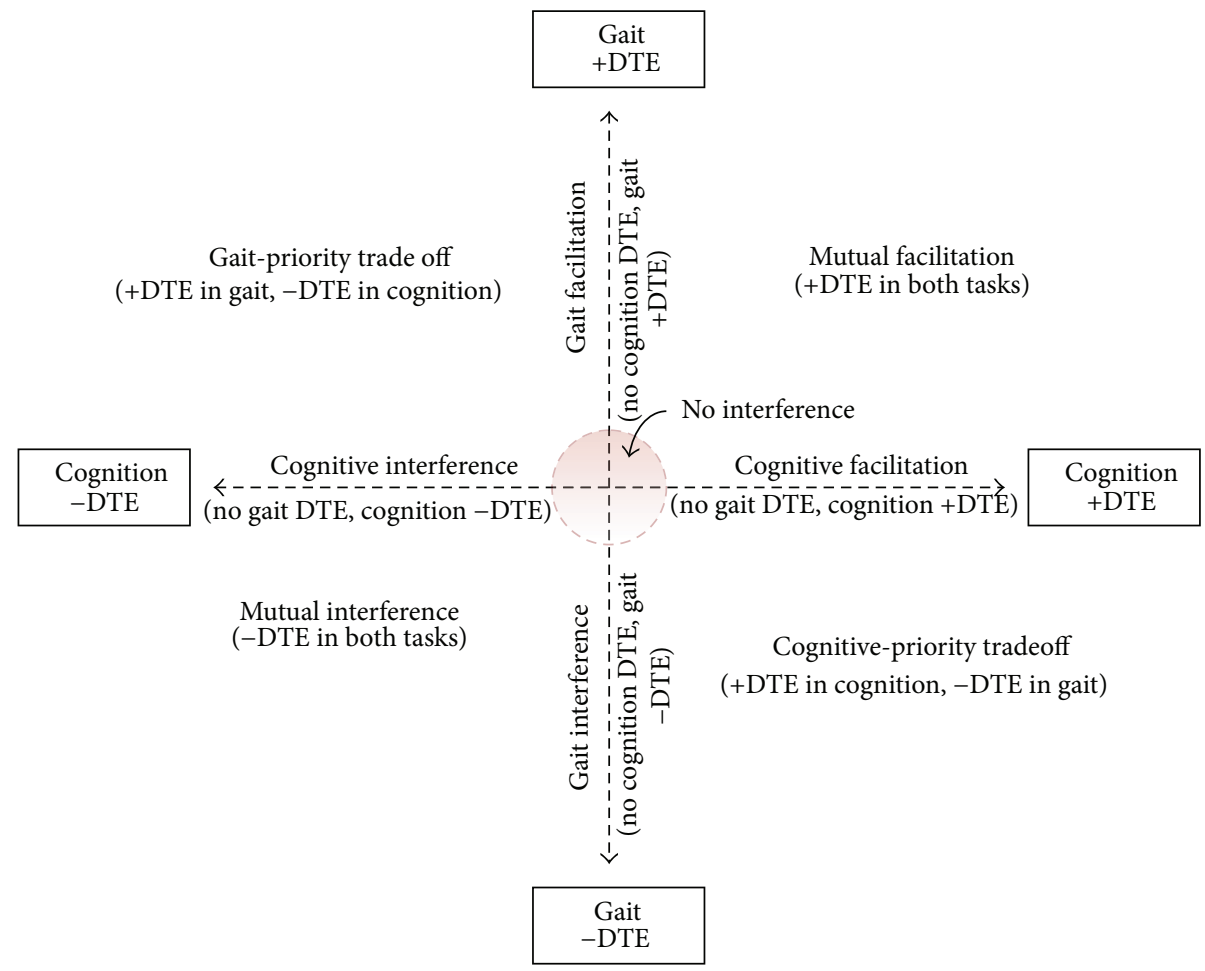

FIGURE 1: Patterns of cognitive-motor interference. Positive values for dual-task effects (DTE) indicate that performance improved in dualtask condition relative to single-task performance; negative values for DTE indicate that performance deteriorated in dual-task condition relative to single-task performance. Figure adapted from conceptual framework of Plummer et al. [9].

and right of the vertical dotted line). Indeed, the most common patterns of cognitive-motor interference were mutual interference (dual-task costs for both tasks), gait interference (dual-task costs on gait with little change in cognitive task performance), and cognitive-priority trade-off (dual-task costs on gait with concurrent dual-task improvements in cognition). Another noteworthy observation of the data in Figure 2 is the variability in dual-task interference across tasks and between participants. The variability suggests that the way in which the participants allocated their attention between the simultaneous tasks changed across tasks and, in some participants, changed over time.

For example, Participant 1 demonstrated gait interference in the Stroop and clock dual-tasks at baseline, but mutual interference after intervention in both the Stroop and clock dual-tasks (Figure 2). Specifically, after the intervention, there were smaller dual-task costs on gait speed in both tasks, but this came at a cost to cognitive-task performance. One 
(a)

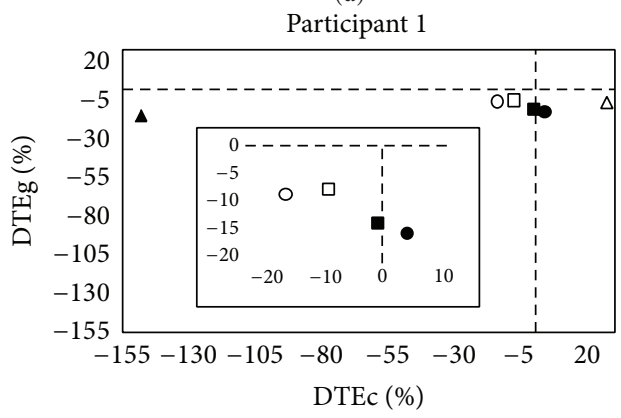

(c)

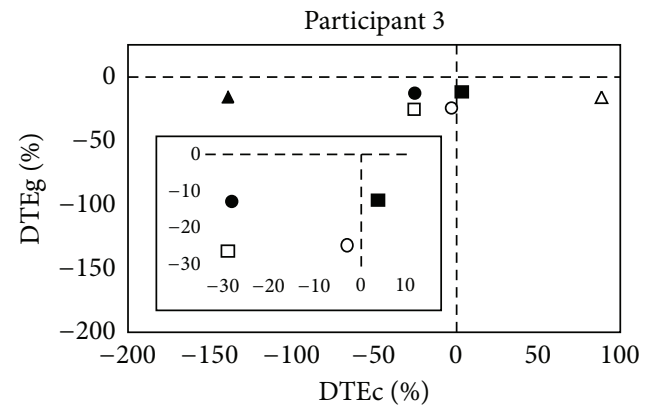

(e)

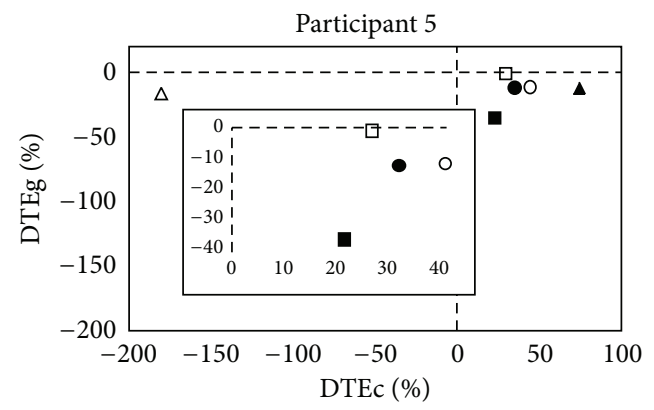

(b)

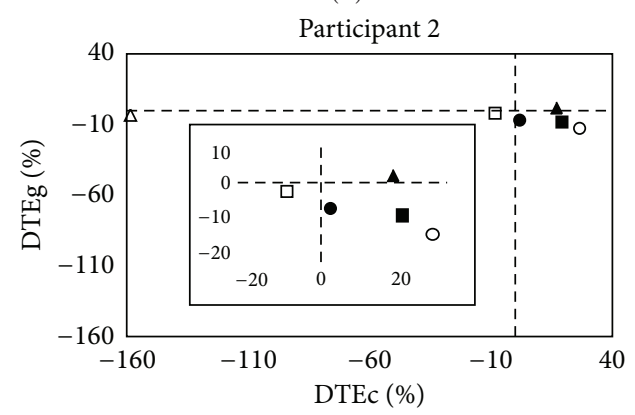

(d)

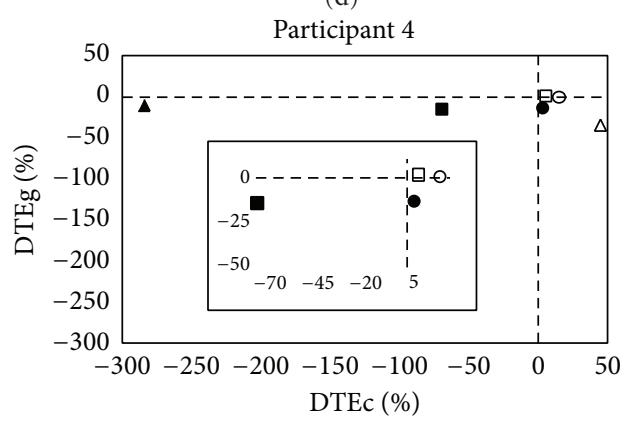

(f)

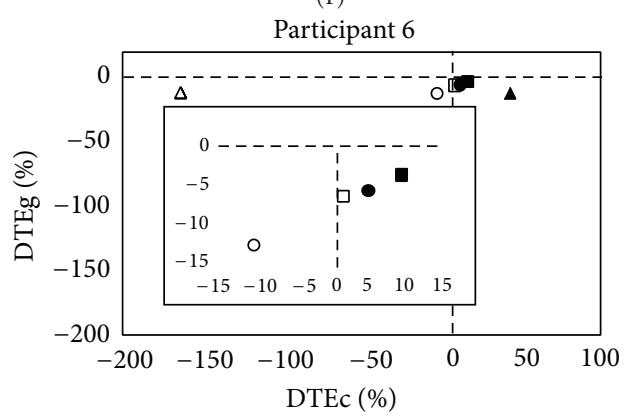

(g)

Participant 7

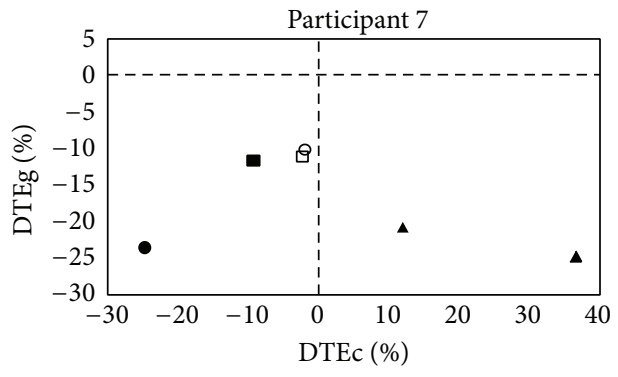

Dual task Before After

$\begin{array}{lll}\text { Stroop } & \mathbf{0} & \square \\ \text { Clock } & \bullet & \bigcirc \\ \text { Speech } & \mathbf{\Delta} & \triangle\end{array}$

FIGURE 2: Plots showing patterns of cognitive-motor interference for each participant for each cognitive-motor dual-task combination before and after the intervention. Dual-task effects (DTE) represent percent change relative to single-task performance and are calculated by dividing the difference between single-task and dual-task values by the single-task value, expressed as a percentage. Positive values for DTE indicate that performance improved in the dual-task condition relative to single-task performance; negative values for DTE indicate that performance deteriorated in dual-task condition relative to single-task performance. DTEg is DTE on gait speed; DTEc is composite DTE for the three cognitive tasks (reaction time and accuracy for Stroop and clock tasks, clauses per utterance and pauses per utterance for spontaneous speech task). 
TABLE 5: Absolute (gait speed, $\mathrm{m} / \mathrm{s}$ ) changes in gait speed for each participant at pre, mid, post intervention and 1-month follow up; and relative (dual-task effects, \%) pre and post intervention. NT indicates not tested.

\begin{tabular}{|c|c|c|c|c|c|c|c|c|c|}
\hline \multirow{2}{*}{ Participant 1} & \multirow[t]{2}{*}{ Single task } & \multicolumn{2}{|c|}{ Dual Stroop } & \multicolumn{2}{|c|}{ Dual clock } & \multicolumn{2}{|c|}{ Dual speech } & \multicolumn{2}{|c|}{ Dual coin } \\
\hline & & & & & & & & & \\
\hline Pre & 0.77 & 0.67 & $(-13.7 \%)$ & 0.66 & $(-14.8 \%)$ & 0.64 & $(-17.0 \%)$ & 0.57 & $(-26.1 \%)$ \\
\hline Mid & 0.74 & 0.69 & & 0.72 & & 0.66 & & 0.65 & \\
\hline Post & 0.75 & 0.69 & $(-7.3 \%)$ & 0.69 & $(-8.1 \%)$ & 0.68 & $(-8.8 \%)$ & 0.58 & $(-22.6 \%)$ \\
\hline Follow up & 0.83 & 0.79 & & 0.71 & & 0.69 & & 0.69 & \\
\hline \multicolumn{10}{|l|}{ Participant 2} \\
\hline Pre & 0.68 & 0.62 & $(-8.2 \%)$ & 0.64 & $(-6.6 \%)$ & 0.69 & $(+1.8 \%)$ & NT & \\
\hline Mid & 0.77 & 0.78 & & 0.75 & & 0.71 & & & \\
\hline Post & 0.70 & 0.69 & $(-2.3 \%)$ & 0.61 & $(-13.0 \%)$ & 0.68 & $(-3.3 \%)$ & & \\
\hline Follow up & 0.83 & 0.75 & & 0.68 & & 0.76 & & & \\
\hline \multicolumn{10}{|l|}{ Participant 3} \\
\hline Pre & 0.58 & 0.51 & $(-12.2 \%)$ & 0.51 & $(-12.6 \%)$ & 0.49 & $(-15.7 \%)$ & NT & \\
\hline Mid & 0.61 & 0.62 & & 0.52 & & 0.52 & & & \\
\hline Post & 0.66 & 0.49 & $(-25.8 \%)$ & 0.50 & $(-24.3 \%)$ & 0.56 & $(-16.0 \%)$ & & \\
\hline Follow up & 0.57 & 0.55 & & 0.51 & & 0.56 & & & \\
\hline \multicolumn{10}{|l|}{ Participant 4} \\
\hline Pre & 0.90 & 0.77 & $(-14.2 \%)$ & 0.78 & $(-13.1 \%)$ & 0.81 & $(-10.1 \%)$ & 0.78 & $(-12.8 \%)$ \\
\hline Mid & 0.75 & 0.73 & & 0.73 & & 0.69 & & 0.65 & \\
\hline Post & 0.92 & 0.93 & $(+1.4 \%)$ & 0.92 & $(0)$ & 0.61 & $(-33.9 \%)$ & 0.92 & $(0)$ \\
\hline Follow up & 1.03 & 1.04 & & 0.96 & & 0.76 & & 0.98 & \\
\hline \multicolumn{10}{|l|}{ Participant 5} \\
\hline Pre & 1.07 & 0.68 & $(-36.0 \%)$ & 0.94 & $(-12.1 \%)$ & 0.94 & $(-12.3 \%)$ & NT & \\
\hline Mid & 0.99 & 0.86 & & 0.91 & & 0.84 & & & \\
\hline Post & 1.02 & 1.01 & $(-1.0 \%)$ & 0.90 & $(-11.4 \%)$ & 0.86 & $(-16.1 \%)$ & & \\
\hline Follow up & NT & NT & & NT & & NT & & & \\
\hline \multicolumn{10}{|l|}{ Participant 6} \\
\hline Pre & 0.97 & 0.93 & $(-3.5 \%)$ & 0.91 & $(-5.5 \%)$ & 0.85 & $(-12.2 \%)$ & NT & \\
\hline Mid & 1.03 & 0.94 & & 0.90 & & 0.87 & & & \\
\hline Post & 1.11 & 1.05 & $(-6.2 \%)$ & 0.98 & $(-12.2 . \%)$ & 0.98 & $(-12.1 \%)$ & & \\
\hline Follow up & 1.05 & 1.02 & & 1.01 & & 0.89 & & & \\
\hline \multicolumn{10}{|l|}{ Participant 7} \\
\hline Pre & 0.92 & 0.81 & $(-11.7 \%)$ & 0.70 & $(-23.5 \%)$ & 0.69 & $(-24.7 \%)$ & NT & \\
\hline Mid & NT & NT & & NT & & NT & & & \\
\hline Post & 0.90 & 0.80 & $(-11.1 \%)$ & 0.81 & $(-10.1 \%)$ & 0.71 & $(-20.8 \%)$ & & \\
\hline Follow up & NT & NT & & NT & & NT & & & \\
\hline \multicolumn{10}{|l|}{ Mean (SD) } \\
\hline Pre & $\mathbf{0 . 8 4}(0.17)$ & $0.71(0.14)$ & $-14.1 \%(10.3)$ & $\mathbf{0 . 7 3}(0.15)$ & $-12.6 \%(5.9)$ & $\mathbf{0 . 7 3}(0.15)$ & $-12.9 \%(8.0)$ & & \\
\hline Post & $\mathbf{0 . 8 7}(0.17)$ & $\mathbf{0 . 8 1}(0.20)$ & $-7.5 \%(9.1)$ & $0.77(0.18)$ & $-\mathbf{1 1 . 3 \%}(7.3)$ & $\mathbf{0 . 7 2}(0.15)$ & $-15.8 \%(9.8)$ & & \\
\hline
\end{tabular}

interpretation is that, at baseline, the participant prioritized his attention during dual-task walking on the cognitive task (illustrated by the absent/minimal DTEc), but after training he was able to divide attention between both tasks. His cognitive-motor interference pattern was different for the speech dual-task; he had mutual interference at baseline (with greater dual-task costs on speech than gait), but demonstrated cognitive-priority trade-off after the intervention (Figure 2). Despite the apparent trade-off of attentional resources during the speech dual-task after training, gait dual-task costs were smaller, suggesting an overall improvement in dual-task capacity in this task.
Summarizing the data illustrated in Figure 2, Participants 2, 4, 5, and 7 demonstrated improved dual-task capacity in the Stroop dual-task after intervention; their dual-task interference "point" for the Stroop dual-task was closer to the no interference region after intervention. Only Participants 4 and 7 showed similar postintervention improvements in the clock dual-task: Participant 4 had only gait interference at baseline, and after intervention he had no interference on gait and some improvement in clock-task performance (positive DTEc, cognitive facilitation); Participant 7 had mutual interference during the clock dual-task at baseline, but less gait interference and no interference 
TABLE 6: Secondary outcomes pre and, post training and, if possible, at one month follow up.

\begin{tabular}{lccccccccc}
\hline & \multicolumn{3}{c}{ Timed up and go (s) } & \multicolumn{3}{c}{ ABC Scale (\%) } & \multicolumn{3}{c}{ SIPSO (max. 40) } \\
& Pre & Post & Follow up & Pre & Post & Follow up & Pre & Post & Follow up \\
\hline Participant 1 & 14.4 & 13.8 & 14.6 & 88.6 & 92.5 & 94.4 & 33 & 27 \\
Participant 2 & 13.5 & 14.3 & 13.5 & 60.6 & 73.8 & 83.1 & 25 & 30 & 32 \\
Participant 3 & 15.0 & 19.3 & 20.1 & 48.8 & 53.1 & 34.4 & 22 & 23 & 22 \\
Participant 4 & 11.3 & 9.0 & 10.2 & 66.9 & 71.9 & 85 & NT & 26 & 32 \\
Participant 5 & 11.5 & 11.5 & NT & 73.1 & 46.3 & 88.8 & 31 & 33 & NT \\
Participant 6 & 10.8 & 9.7 & 10.2 & 75 & 91.6 & NT & 34 & 33 \\
Participant 7 & 10.5 & 10.5 & NT & 81.9 & 81.9 & & 26.4 & 28.1 & NT \\
\hline Mean & 12.4 & 12.5 & & 70.7 & 73.0 & & 26 & 30 \\
Median & 11.5 & 11.5 & & 73.1 & 73.8 & & & 26 \\
\hline
\end{tabular}

ABC: activities-specific balance confidence scale, SIPSO: subjective index of physical and social outcome, NT: not tested.

in cognition after intervention. Participants 2, 3, and 6 were similar to Participant 1 described above in that they demonstrated a change in pattern of interference for the clock dual-task, suggestive of a change in spontaneous prioritization of attention after intervention. However, the pattern change was not consistent (see Figure 2).

DTE on speech measures was typically much larger than those for the Stroop and clock task measures. The participants were also highly variable in whether they had negative or positive dual-task effects on measures of speech performance, and the pattern changed after intervention in most participants. For example, in Participants 1, 3, and 4, the pattern of dual-task interference in the speech dual-task changed from mutual interference to cognitive-priority tradeoff; whereas in Participants 5 and 6, the patterns changed from cognitive-priority trade-off to mutual interference (in both cases, DTEg did not change but DTEc shifted from positive to negative).

6.3. Balance and Participation. Five of the seven participants had increased balance confidence (ABC scores) after intervention (Table 6), but only Participants 2 and 6 had increases that exceed the standard error of measurement (6.81 points) for the $\mathrm{ABC}$ in chronic stroke [33]. Compared to only two participants at baseline, four of the five participants tested 1 month after the intervention had $A B C$ scores $>80 \%$, indicative of high physical functioning [34] and low likelihood of recurrent falls [35]. Participant 3 was low functioning at baseline $(\mathrm{ABC}<50 \%)$; this improved slightly after intervention, but was worse than baseline at follow up. The reason why Participant 5 scored so low on the $\mathrm{ABC}$ scale after intervention is unclear. Three participants had increased SIPSO scores after intervention, suggestive of higher levels of social and physical reintegration, but the minimal clinically important difference values for this measure are not known. There were no meaningful changes in the TUG after intervention; the only participant whose pre-post change in TUG exceeded the minimal detectable change value for chronic stroke (2.9 seconds) [36] was Participant 3, whose baseline TUG indicated high fall risk [37]. He showed decline in functional mobility after training (4.3 seconds slower). Indeed, Participant 3 disclosed during the postintervention evaluation that he had experienced a fall (with associated vertigo) at home since the midpoint assessment.

6.4. Feasibility and Safety Outcomes. Most participants reported small increases in mental and physical fatigue in each session, with the ratings of physical fatigue typically greater than those of mental fatigue. The participants also reported low levels of difficulty, anxiety, and fear of falling. Participant 3 had the highest average ratings of perceived difficulty (mean: $55.3 \mathrm{~mm}$, range: 34-68), anxiety (mean: $55.0 \mathrm{~mm}$, range: $37-70$ ), and fear of falling (mean: $47.5 \mathrm{~mm}$, range: $28-72$ ). None of the participants missed any session. Other than Participant 3 who reported a fall without injury at home during the second half of the intervention period, there were no adverse events reported. All participants indicated that they were "extremely satisfied" $(n=4)$ or "satisfied" $(n=3)$ with the treatment.

\section{Discussion}

This case series is the first study to examine cognitivemotor dual-task gait training in community-dwelling adults with stroke. The findings from this report provide evidence that cognitive-motor dual-task gait training is feasible in the first 12 months after stroke, and that cognitive-motor dual-task gait training can improve dual-task walking speed. The most consistent improvements were observed for the Stoop dual-task; improvements in dual-task walking speed during the clock and speech tasks were more variable. This may indicate low transfer of training to untrained cognitivemotor dual-tasks. The cognitive tasks used in the DTGT intervention largely involved executive functioning (which is a key function required for the Stroop task), thus it is possible that improvements in the Stroop dual-task were greater than the clock and speech dual-tasks because it resembled most closely the types of cognitive activities used during DTGT. Another possible explanation for the smaller and less consistent changes in dual-task performance in the clock and speech task, however, is that these tasks were relatively more difficult than the Stroop task. Previous research has shown significantly greater dual-task effects on gait in the 
clock [38] and speech tasks [8, 39] in people with stroke and healthy adults. Regardless of whether this finding can be attributed to poor transfer of training to untrained dual-task combinations, or differences in cognitive-task difficulty, the practical implication is that it may be important to include a wider range of cognitive tasks during DTGT to maximize transfer to different cognitive-motor dual-task combinations. Alternatively, therapists may choose to assess dual-task performance in a range of different dual-task combinations and then select dual-task activities for intervention that specifically target the person's greatest limitations.

An interesting finding from this case series is that most participants did not demonstrate remarkable improvements in single-task walking speed after the intervention. This may be due to the fact that there was no single-task practice during the DTGT sessions; the training focused exclusively on dualtask practice of gait. If gains in single-task walking speed are an important therapy goal, then it may be necessary to include both single and dual-task practice components in a dual-task gait training program. This may be a worthy consideration for future DTGT interventions, since single-task gait speed has been found to be correlated with dual-task costs on gait speed $[39,40]$. Nevertheless, most of the participants in this case series showed improvements in dual-task walking in at least one of the dual-tasks.

Despite the improvements in the absolute and relative dual-task effects on gait speed by most of the participants in this study, our analysis of the patterns of cognitivemotor interference showed tremendous variability in dualtask performance and in the effects of the intervention on dual-task walking. While some participants showed evidence of improved dual-task capacity (e.g., decreased dual-task costs in both tasks), others demonstrated differences in the way they performed the task with no clear evidence of improvement in dual-task capacity. It is unclear whether a change in the pattern of cognitive-motor interference is indicative of a change in dual-task ability, and unfortunately this cannot be elucidated from the current data. However, our unique analysis highlights several important factors to be considered in future studies of dual-task gait training interventions. First, analysis of dual-task effects on gait may be inadequate to assess changes in dual-task performance. Performance on both gait and nongait tasks must be analyzed, and changes relative to each other should be considered when interpreting effects of treatment on dual-task performance. Second, reliability of dual-task performance needs to be established. To date, there have been no studies that have examined the reliability of dual-task performance: do individuals perform a particular dual-task the same way on multiple occasions? Until this is determined, it is not possible to conclude that changes in the pattern of interference are due to the intervention or just to a different strategy on a different day. This raises a third issue: the influence of instructions on dual-task performance. We did not provide any specific instruction about which task the individual should prioritize during the dual-task assessments. We were interested in examining the "default" performance of the participants. Lack of specific instruction about which task to prioritize means that each individual shall decide how to prioritize their attention in a given dual-task situation. While it is reasonable to assume that dual-task practice (i.e., dual-task intervention) may change the way a person chooses to spontaneously allocate their attention during dual-task walking, there are several other factors that may influence attention allocation in a particular dual-task situation, such as the perceived difficulty or importance of one task over another. Does dual-task training change a person's preferred attention allocation strategy or improve the efficiency and/or capacity for attention shifting, or simply improve gait automaticity such that attention can now be more easily allocated to other tasks?

Recent research has suggested that the ability to flexibly allocate attention between the two tasks during dual-task walking may be an important factor influencing dual-task interference [41]. It is not yet known whether individuals with stroke have the ability to voluntarily adapt their attentional focus during dual-task walking. While our results demonstrate variability within and between individuals in the way attention may be prioritized in different dual-tasks, determining the influence of dynamic attentional prioritization on dual-task performance will be important in order to establish the optimal instructions to use in dual-task assessment and training after stroke.

A potentially important clinical implication of the observations from this case series concerns the appropriateness of DTGT for individuals with more severe balance and gait deficits and/or limitations in cognitive ability. Participant 3 was the slowest walker and was at high risk for falls, with a baseline TUG greater than 15 seconds [37], and he had the lowest score on the MoCA. Relative to baseline, this participant had greater dual-task costs on gait speed in all three cognitive-motor dual-tasks after intervention, as well as clinically significant decline in the TUG. Furthermore, he perceived the intervention to be relatively difficult with some associated anxiety and fear of falling. It is possible that for individuals with considerable gait and balance impairments, improvements in walking and balance in undistracted conditions are needed before DTGT can be effectively implemented; or it may be that DTGT is not appropriate for individuals with a combination of physical and cognitive impairments. The findings from this case series have informed the selection criteria in the followup randomized controlled trial of dual-task gait training versus single-task gait training in community-dwelling stroke survivors within one year after stroke [42].

A limitation of this case series is that we did not include any postintervention assessments of cognition. In future, it would be of interest to determine whether DTGT has any effect on cognitive domains, such as executive function. The nature of the case series also limits the generalizability of the findings to other individuals with stroke. An unexpected scenario was that all of the participants in this case series were male. This is important because gender differences in gait-related dual-task interference have been reported among healthy adults $[43,44]$. In general, there were only small changes in the self-reported measure of participation used in this study. Examination of spontaneous physical activity using activity monitoring devices may yield 
more accurate information about whether improvements in dual-task walking are translated to increased community ambulation. One of the participants (P5) in this case series for whom we captured physical activity data using the PAMSys (Biosensics, Cambridge, MA; data not shown) demonstrated notable increases in walking and standing activity, number of episodes of walking per day, and number of steps per day after the intervention [45].

\section{Conclusion}

The findings of this case series demonstrate the feasibility of DTGT in community-dwelling stroke survivors within one year of stroke. Our observations suggest that the potential benefits of DTGT may be limited in individuals with poor balance, slow usual walking speed, and/or impaired cognitive ability. The type and variety of cognitive tasks used during DTGT may influence transfer to untrained dual-task combinations. Importantly, even though dual-task costs on gait speed may improve with DTGT, the pattern of DTE suggests that changes in overall dual-task performance with intervention are highly variable.

\section{Conflict of Interests}

The authors declare that there is no conflict of interests regarding the publication of this paper.

\section{Acknowledgments}

The authors gratefully acknowledge the assistance of Keith Poulin, Gillian Shea, Colleen Dowd, Jacqueline Reinschmidt, Joy Huebner, Laura Hennessey, and Celina Cerf. This research was supported by the Kenerson Faculty Scholarship (P. Plummer).

\section{References}

[1] A. Bowen, R. Wenman, J. Mickelborough, J. Foster, E. Hill, and R. Tallis, "Dual-task effects of talking while walking on velocity and balance following a stroke," Age and Ageing, vol. 30, no. 4, pp. 319-323, 2001.

[2] J. Cockburn, P. Haggard, J. Cock, and C. Fordham, "Changing patterns of cognitive-motor interference (CMI) over time during recovery from stroke," Clinical Rehabilitation, vol. 17, no. 2, pp. 167-173, 2003.

[3] A. Dennis, H. Dawes, C. Elsworth et al., "Fast walking under cognitive-motor interference conditions in chronic stroke," Brain Research, vol. 1287, pp. 104-110, 2009.

[4] P. Haggard, J. Cockburn, J. Cock, C. Fordham, and D. Wade, "Interference between gait and cognitive tasks in a rehabilitating neurological population," Journal of Neurology Neurosurgery and Psychiatry, vol. 69, no. 4, pp. 479-486, 2000.

[5] D. Hyndman, A. Ashburn, L. Yardley, and E. Stack, "Interference between balance, gait and cognitive task performance among people with stroke living in the community," Disability and Rehabilitation, vol. 28, no. 13-14, pp. 849-856, 2006.

[6] S. Kemper, J. McDowd, P. Pohl, R. Herman, and S. Jackson, "Revealing language deficits following stroke: the cost of doing two things at once," Aging, Neuropsychology, and Cognition, vol. 13 , no. 1, pp. 115-139, 2006.

[7] P. Plummer-D’Amato, L. J. P. Altmann, A. L. Behrman, and M. Marsiske, "Interference between cognition, double-limb support, and swing during gait in community-dwelling individuals poststroke," Neurorehabilitation and Neural Repair, vol. 24, no. 6, pp. 542-549, 2010.

[8] P. Plummer-D’Amato, L. J. P. Altmann, D. Saracino, E. Fox, A. L. Behrman, and M. Marsiske, "Interactions between cognitive tasks and gait after stroke: a dual task study," Gait and Posture, vol. 27, no. 4, pp. 683-688, 2008.

[9] P. Plummer, G. Eskes, S. Wallace et al., "Cognitive-motor interference during functional mobility after stroke: state of the science and implications for future research," Archives of Physical Medicine and Rehabilitation, vol. 94, pp. 2565-2574, 2013.

[10] P. Silsupadol, A. Shumway-Cook, V. Lugade et al., "Effects of single-task versus dual-task training on balance performance in older adults: a double-blind, randomized controlled trial," Archives of Physical Medicine and Rehabilitation, vol. 90, no. 3, pp. 381-387, 2009.

[11] P. Silsupadol, K.-C. Siu, A. Shumway-Cook, and M. H. Woollacott, "Training of balance under single- and dual-task conditions in older adults with balance impairment," Physical Therapy, vol. 86, no. 2, pp. 269-281, 2006.

[12] C. G. Canning, L. Ada, and E. Woodhouse, "Multiple-task walking training in people with mild to moderate Parkinson's disease: a pilot study," Clinical Rehabilitation, vol. 22, no. 3, pp. 226-233, 2008.

[13] S. G. Brauer and M. E. Morris, "Can people with Parkinson's disease improve dual tasking when walking?" Gait and Posture, vol. 31, no. 2, pp. 229-233, 2010.

[14] J. J. Evans, E. Greenfield, B. A. Wilson, and A. Bateman, "Walking and talking therapy: improving cognitive-motor dualtasking in neurological illness," Journal of the International Neuropsychological Society, vol. 15, no. 1, pp. 112-120, 2009.

[15] Y.-R. Yang, Y.-C. Chen, C.-S. Lee, S.-J. Cheng, and R.-Y. Wang, "Dual-task-related gait changes in individuals with stroke," Gait and Posture, vol. 25, no. 2, pp. 185-190, 2007.

[16] E. A. Maylor and A. M. Wing, "Age differences in postural stability are increased by additional cognitive demands," Journals of Gerontology B Psychological Sciences and Social Sciences, vol. 51, no. 3, pp. P143-P154, 1996.

[17] R. Holtzer, J. Verghese, X. Xue, and R. B. Lipton, "Cognitive processes related to gait velocity: results from the Einstein aging study," Neuropsychology, vol. 20, no. 2, pp. 215-223, 2006.

[18] A. M. Gentile, "Skill acquisition: action, movement, and neuromotor processes," in Movement Science: Foundations For Physical Therapy Rehabilitation, J. Carr and R. Shepherd, Eds., Aspen Publishers, Gaithersburg, Md, USA, 2000.

[19] K.-C. Siu, R. D. Catena, L.-S. Chou, P. van Donkelaar, and M. H. Woollacott, "Effects of a secondary task on obstacle avoidance in healthy young adults," Experimental Brain Research, vol. 184, no. 1, pp. 115-120, 2008.

[20] N. Shkuratova, M. E. Morris, and F. Huxham, "Effects of age on balance control during walking," Archives of Physical Medicine and Rehabilitation, vol. 85, no. 4, pp. 582-588, 2004.

[21] S. O'Shea, M. E. Morris, and R. Iansek, "Dual task interference during gait in people with Parkinson disease: effects of motor versus cognitive secondary tasks," Physical Therapy, vol. 82, no. 9, pp. 888-897, 2002. 
[22] J. Perry, M. Garrett, J. K. Gronley, and S. J. Mulroy, "Classification of walking handicap in the stroke population," Stroke, vol. 26, no. 6, pp. 982-989, 1995.

[23] V. E. Kelly, A. A. Janke, and A. Shumway-Cook, "Effects of instructed focus and task difficulty on concurrent walking and cognitive task performance in healthy young adults," Experimental Brain Research, vol. 207, no. 1-2, pp. 65-73, 2010.

[24] D. Podsiadlo and S. Richardson, "The timed "Up and Go": a test of basic functional mobility for frail elderly persons," Journal of the American Geriatrics Society, vol. 39, no. 2, pp. 142-148, 1991.

[25] L. E. Powell and A. M. Myers, "The Activities-specific Balance Confidence (ABC) scale," Journals of Gerontology A Biological Sciences and Medical Sciences, vol. 50, no. 1, pp. M28-M34, 1995.

[26] R. Trigg and V. A. Wood, "The Subjective Index of Physical and Social Outcome (SIPSO): a new measure for use with stroke patients," Clinical Rehabilitation, vol. 14, no. 3, pp. 288-299, 2000.

[27] Z. S. Nasreddine, N. A. Phillips, V. Bédirian et al., "The Montreal Cognitive Assessment, MoCA: a brief screening tool for mild cognitive impairment," Journal of the American Geriatrics Society, vol. 53, no. 4, pp. 695-699, 2005.

[28] J. R. Stroop, "Studies of interference in serial verbal reactions," Journal of Experimental Psychology, vol. 18, no. 6, pp. 643-662, 1935.

[29] W. C. Shipley, "A self-administering scale for measuring intellectual impairment and deterioration," The Journal of Psychology, vol. 9, no. 2, pp. 371-377, 1940.

[30] A. R. Fugl Meyer, L. Jaasko, and I. Leyman, “The post stroke hemiplegic patient. I. A method for evaluation of physical performance," Scandinavian Journal of Rehabilitation Medicine, vol. 7, no. 1, pp. 13-31, 1975.

[31] J. A. Yesavage, T. L. Brink, and T. L. Rose, "Development and validation of a geriatric depression screening scale: a preliminary report," Journal of Psychiatric Research, vol. 17, no. 1, pp. 37-49, 1982.

[32] A. Schmid, P. W. Duncan, S. Studenski et al., "Improvements in speed-based gait classifications are meaningful," Stroke, vol. 38, no. 7, pp. 2096-2100, 2007.

[33] E. M. Botner, W. C. Miller, and J. J. Eng, "Measurement properties of the activitites-specific balance confidence scale among individuals with stroke," Disability and Rehabilitation, vol. 27, no. 4, pp. 156-163, 2005.

[34] A. M. Myers, P. C. Fletcher, A. H. Myers, and W. Sherk, "Discriminative and evaluative properties of the activities-specific balance confidence (ABC) scale," Journals of Gerontology A Biological Sciences and Medical Sciences, vol. 53, no. 4, pp. M287M294, 1998.

[35] M. Beninato, L. G. Portney, and P. E. Sullivan, "Using the international classification of functioning, disability and health as a framework to examine the association between falls and clinical assessment tools in people with stroke," Physical Therapy, vol. 89, no. 8, pp. 816-825, 2009.

[36] U.-B. Flansbjer, A. M. Holmbäck, D. Downham, C. Patten, and J. Lexell, "Reliability of gait performance tests in men and women with hemiparesis after stroke," Journal of Rehabilitation Medicine, vol. 37, no. 2, pp. 75-82, 2005.

[37] E. Nordin, N. Lindelöf, E. Rosendahl, J. Jensen, and L. LundinOlsson, "Prognostic validity of the Timed Up-and-Go test, a modified Get-Up-and-Go test, staff's global judgement and fall history in evaluating fall risk in residential care facilities," Age and Ageing, vol. 37, no. 4, pp. 442-448, 2008.
[38] P. Plummer-D’Amato, B. Brancato, M. Dantowitz, S. Birken, C. Bonke, and E. Furey, "Effects of gait and cognitive task difficulty on cognitive-motor interference in aging," Journal of Aging Research, vol. 2012, Article ID 583894, 8 pages, 2012.

[39] P. Plummer-D’Amato, L. J. P. Altmann, and K. Reilly, “Dual-task effects of spontaneous speech and executive function on gait in aging: exaggerated effects in slow walkers," Gait and Posture, vol. 33, no. 2, pp. 233-237, 2011.

[40] P. Plummer-D’Amato and L. J. P. Altmann, "Relationships between motor function and gait-related dual-task interference after stroke: a pilot study," Gait and Posture, vol. 35, no. 1, pp. 170-172, 2012.

[41] K.-C. Siu, L.-S. Chou, U. Mayr, P. van Donkelaar, and M. H. Woollacott, "Does inability to allocate attention contribute to balance constraints during gait in older adults?" Journals of Gerontology A Biological Sciences and Medical Sciences, vol. 63, no. 12, pp. 1364-1369, 2008.

[42] P. Plummer-D’Amato, A. Kyvelidou, D. Sternad, B. Najafi, R. M. Villalobos, and D. Zurakowski, “Training dual-task walking in community-dwelling adults within 1 year of stroke: a protocol for a single-blind randomized controlled trial," BMC Neurology, vol. 12, p. 129, 2012.

[43] G. Yogev-Seligmann, Y. Rotem-Galili, A. Mirelman, R. Dickstein, N. Giladi, and J. M. Hausdorff, "How does explicit prioritization alter walking during dual-task performance? Effects of age and sex on gait speed and variability," Physical Therapy, vol. 90, no. 2, pp. 177-186, 2010.

[44] J. H. Hollman, J. W. Youdas, and D. J. Lanzino, "Gender differences in dual task gait performance in older adults," American Journal of Men's Health, vol. 5, no. 1, pp. 11-17, 2011.

[45] P. Plummer-D’Amato, R. Villalobos, M. Vayda et al., "Feasibility of training dual task walking after stroke," Archives of Physical Medicine and Rehabilitation, vol. 92, no. 10, pp. 1717-1718, 2011. 


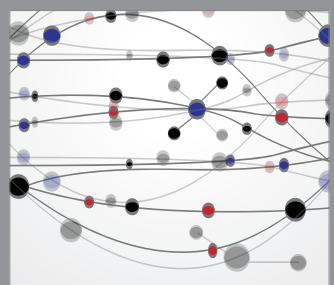

The Scientific World Journal
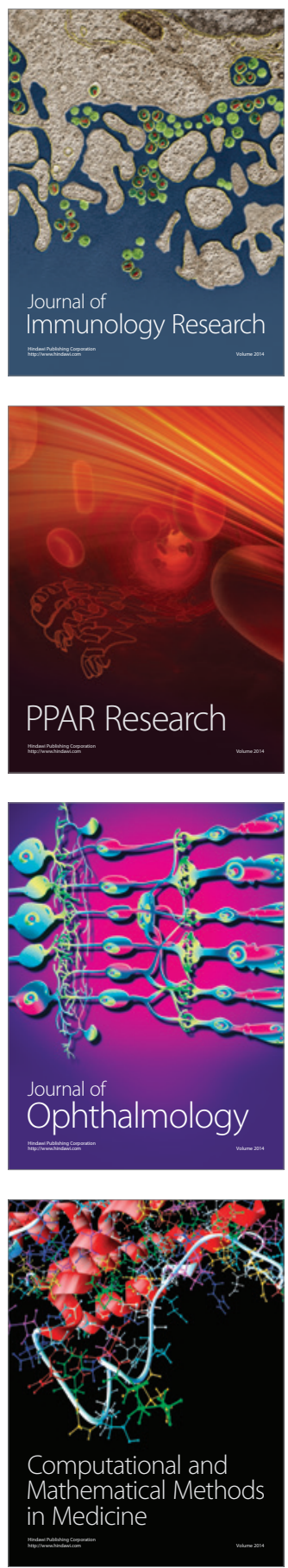

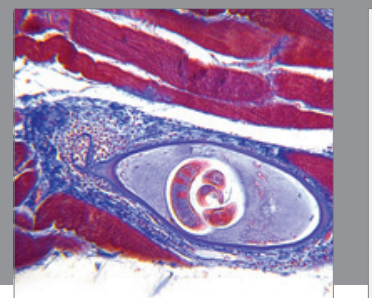

Gastroenterology

Research and Practice
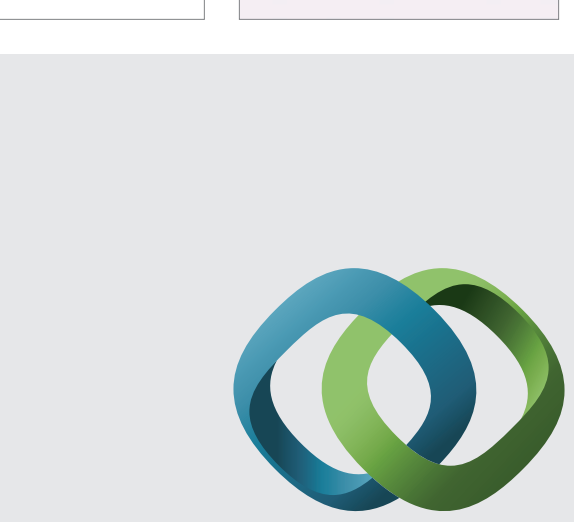

\section{Hindawi}

Submit your manuscripts at

http://www.hindawi.com
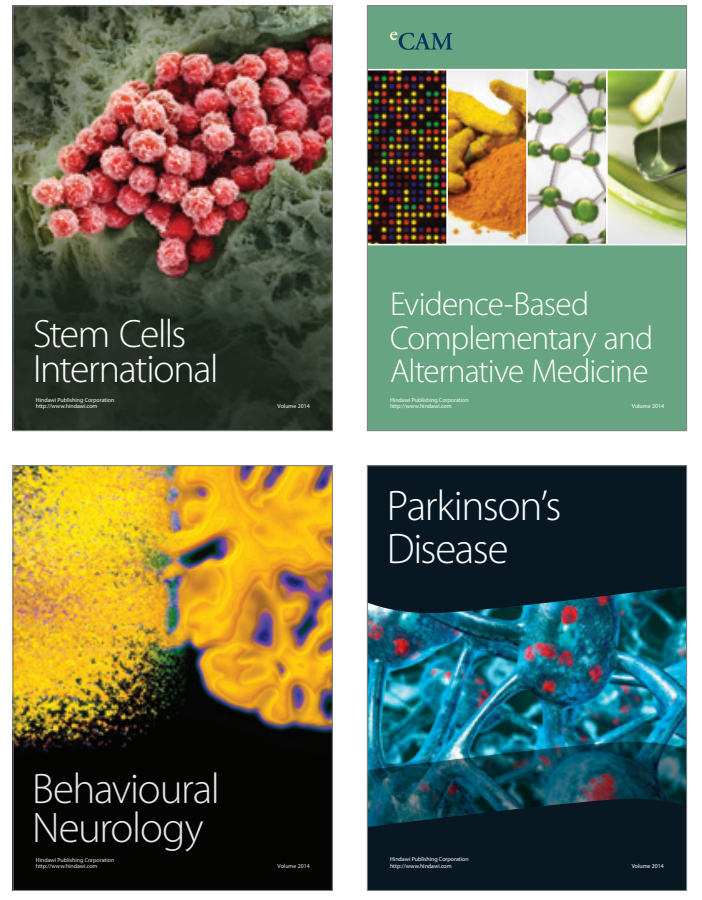
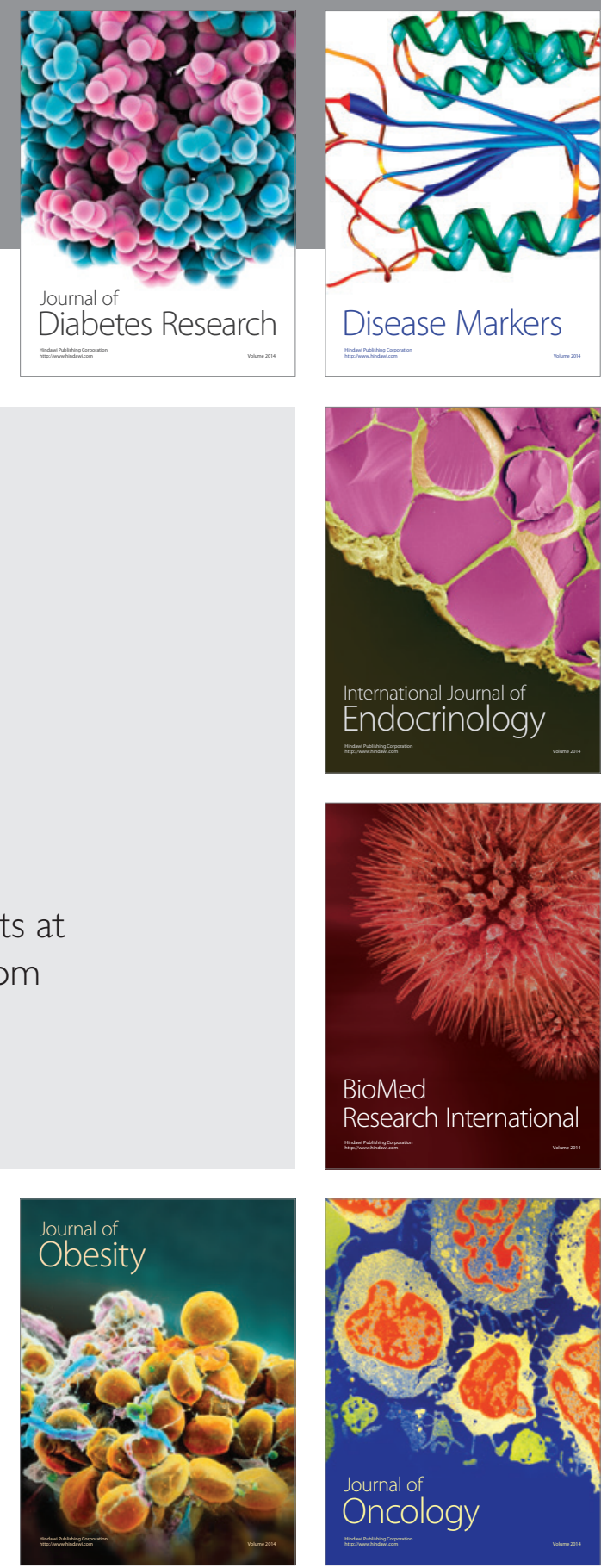

Disease Markers
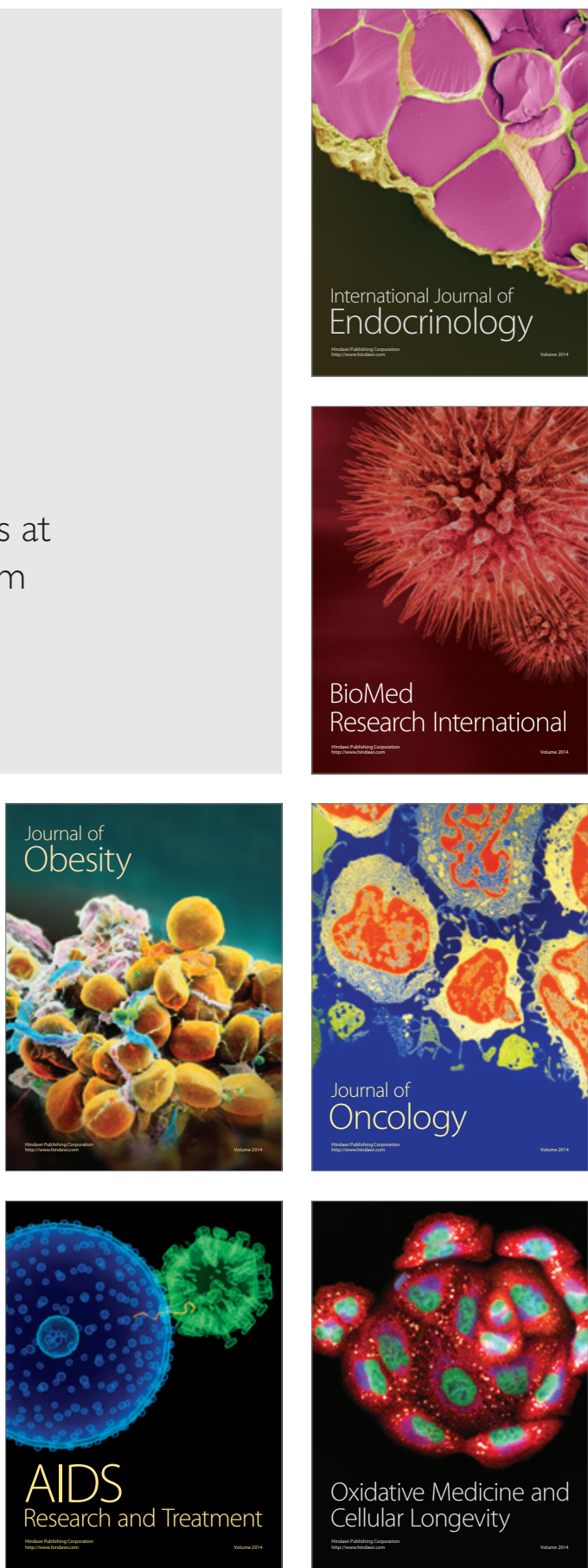